\section{(C) \\ OPEN ACCESS}

\title{
Plasmablastic lymphoma masquerading solitary plasmacytoma in an immunocompetent patient
}

\author{
Rodrigo Diaz, ${ }^{1,2}$ Julan Amalaseelan, ${ }^{2}$ Louise Imlay-Gillespie ${ }^{3}$
}

\begin{abstract}
${ }^{1}$ Radiation Oncology, Northern NSW Local Health District, Lismore, New South Wales, Australia

${ }^{2}$ Radiation Oncology, Northern NSW Cancer Institute, Lismore, New South Wales, Australia ${ }^{3}$ Lismore Cancer Care and Haematology Unit, Northern NSW Local Health District, Lismore, New South Wales, Australia
\end{abstract}

\section{Correspondence to Dr Rodrigo Diaz, drrdiaz@gmail.com}

Accepted 25 September 2018

Check for updates

(c) BMJ Publishing Group Limited 2018. Re-use permitted under CC BY-NC. No commercial re-use. See rights and permissions. Published by BMJ.

\section{To cite: Diaz R,}

Amalaseelan $\mathrm{J}$,

Imlay-Gillespie L. BMJ Case Rep Published Online First: [please include Day Month Year]. doi:10.1136/bcr-2018 225374

\section{SUMMARY}

We report a case of a middle-aged woman who initially presented with a painful solitary destructive lesion at fifth lumbar vertebra. The initial diagnosis of plasma cell neoplasm was made based on limited histological information obtained from fragmented tissue sample. Clinicopathological findings were consistent with a solitary plasmacytoma, and she was treated with definitive radiotherapy. A month after completing radiotherapy, she was found to have multiple liver lesions. Subsequent liver biopsy confirmed plasmablastic lymphoma (PBL). She was treated with multiple lines of chemo/immunotherapy regimens with limited or no response. She died of progression of liver lesions causing hepatic failure 16 months post diagnosis. Because of its rarity and heterogeneous presentations, PBL could easily be overlooked clinically and pathologically in immunocompetent patients. Diagnosis of PBL should be considered when there is coexpression of myeloma and lymphoma immune markers.

\section{BACKGROUND}

Plasmablastic lymphoma (PBL) is distinct type of diffuse large B cell lymphoma (DLBCL) predominantly seen in HIV-positive patients. ${ }^{1}$ The diagnosis of PBL could be a challenge due to its overlapping characterises with those of myeloma and lymphoma. Because of its rarity, no standard management strategy has been established. A review by Morscio et al showed a median overall survival (OS) of 8 months. It also revealed HIV-negative patients have slightly better OS (11 months) compared with HIV-positive patients (10 months). ${ }^{2}$

HIV-negative PBL has been shown to affect relatively higher proportion of female patients in contrast to HIV-positive patients. The median age of HIV-negative PBL patients was 55 years. ${ }^{3} \mathrm{PBL}$ in immunocompetent patients appeared to be more heterogeneous in terms of sites of involvement. ${ }^{3}$

We describe a HIV-negative case of PBL who initially appeared to have solitary plasmacytoma. Three months later, she was found to have stage IV PBL. She was treated with different chemotherapy and immunotherapy combinations and survived for 16 months.

\section{CASE PRESENTATION}

A middle-aged previously healthy woman initially presented with 2 months history of leftsided sciatica-like pain. The pain then progressed to involve lower back. She did not have any B symptoms. The initial CT of lumbar spine showed a pathological fracture in L5. Subsequent MRI of lumbosacral spine demonstrated posterior extradural mass at L5 level with compression of L5 nerve root (figure 1). She proceeded to have laminectomy and surgical decompression. Intraoperatively fibrous organising lesion intimately associated with theca at S1 level was identified. The culture from surgical material grew Staphylococcus epidermidis, probably from contamination. Nevertheless, she was treated with antibiotic therapy for extended period.

The histopathological examination of surgical specimen revealed poorly differentiated malignancy, likely haematological origin (figure 2). Immunophenotyping showed positive staining for CD45, CD138 and vimentin and negative staining for CD20, cytokeratin and thyroid transcription

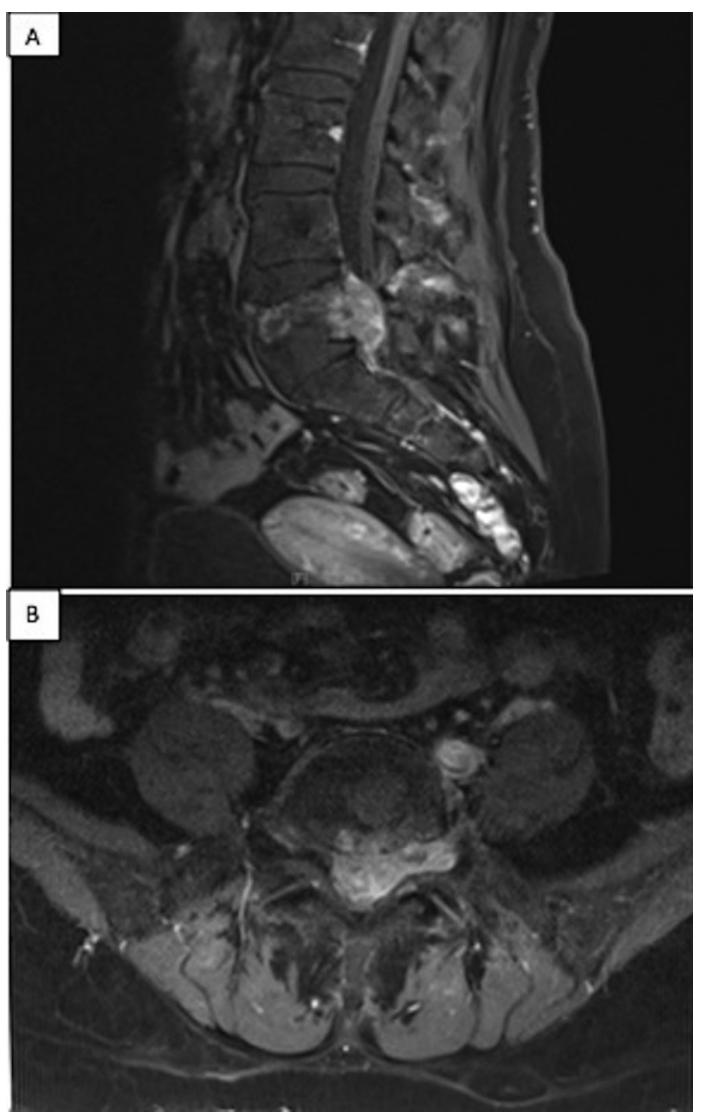

Figure 1 Sagittal section of T1 MRI with Gd contrast (A) reveals an enhancing extradural soft tissue mass at the level of $L 5$. The axial view (B) revealed compression of the left $L 5$ nerve root. 


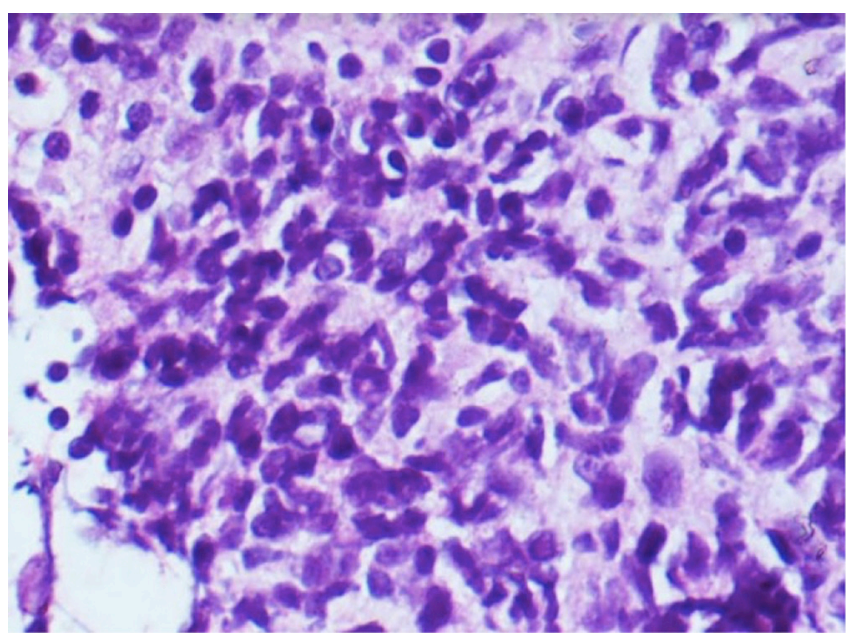

Figure 2 Histological study of the lumbar lesion. A high-power view of the sample showing a poorly differentiated tumour composed of medium to large cells.

factor 1 (TTF-1). The ki67 index was high (70\%). No fluorescence in situ hybridization (FISH) panel was performed and the specimen was negative for Epstein-Barr virus assessed by the Epstein-Barr virus encoded RNAs (EBER) in situ hybridisation. The myeloid markers were negative and a diagnosis of plasma cell neoplasm was made. Subsequent (positron emission tomography) PET did not show any other fluorodeoxyglucose (FDG) avid areas apart from L5 lesion with a maximum standardised uptake value (SUVmax) of 11.5. Bone marrow aspirate showed no increased plasma cells, no clonality and normal cytogenetics. Capillary serum electrophoresis and serum-free light chains did not demonstrate a paraprotein or light chain excess. Full blood count $(\mathrm{FBC})$, liver function including lactate dehydrogenase $(\mathrm{LDH})$ level were within normal range.

She received $45 \mathrm{~Gy}$ in 25 fractions of radical radiotherapy to the L5 region. Her back pain and sciatica completely resolved after the radiotherapy.

Six weeks after completing radiotherapy (4 months since initial diagnosis), she developed upper abdominal pain and non-specific flu-like symptoms. A restaging PET demonstrated complete metabolic response on the L5 region. However, multiple new liver lesions (figure 3 ) were identified. In addition, a new FDG avid left internal mammary node and a bony lesion

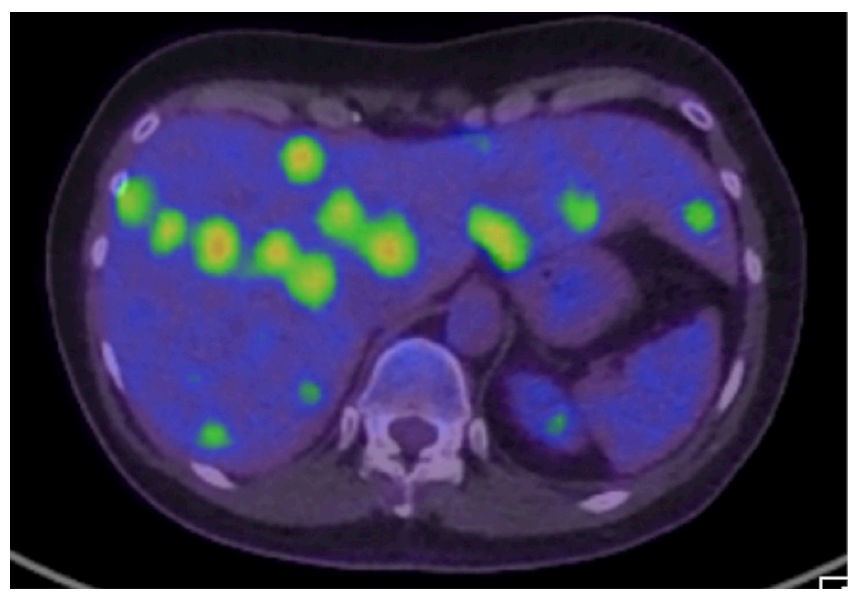

Figure $3 \mathrm{CT} /$ positron emission tomography demonstrates multiple FDG avid liver lesions. FDG, fluorodeoxyglucose.
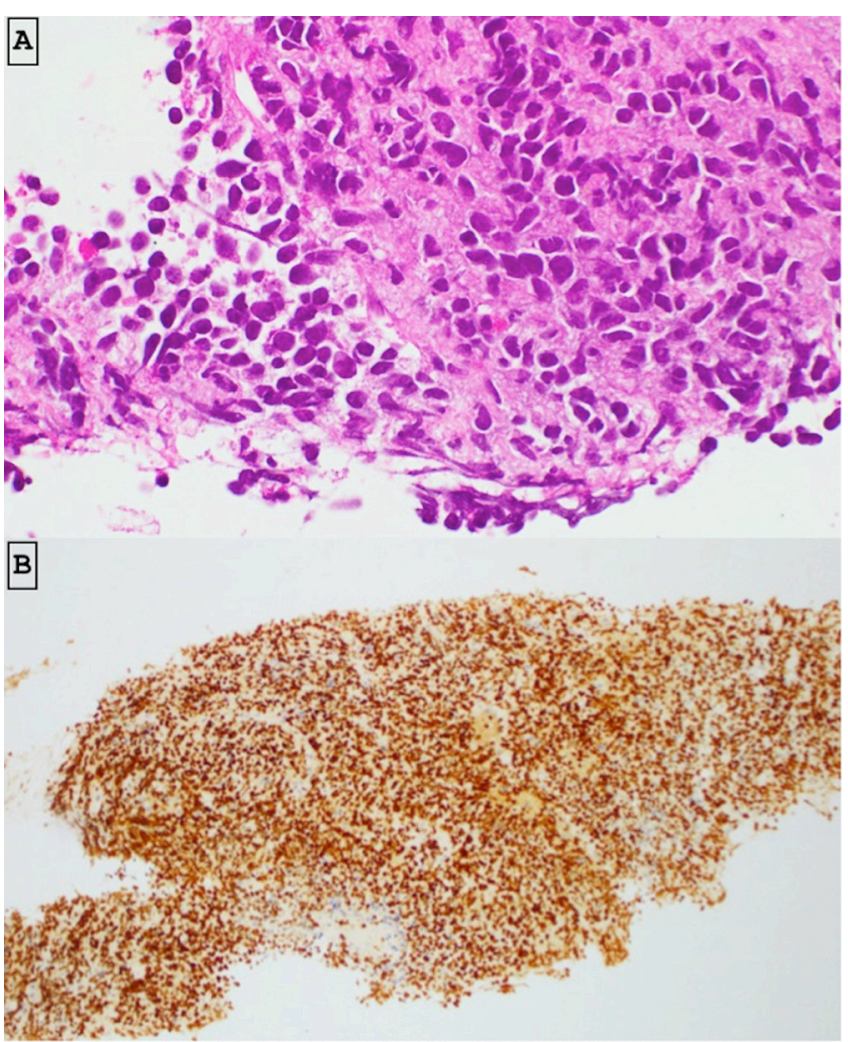

Figure 4 Histological and immunohistochemical study of the liver lesion. (A) Histology showed high-grade malignant tumour cells. The tumour consists of enlarged cells with hyperchromatic angulate nuclei and modest volumes of eosinophilic cytoplasm. (B) The tumour cells express positive staining for c-Myc ( $>80 \%$ cells).

at the right scapula were noted. Her LDH level was elevated to $868 \mathrm{U} / \mathrm{L}$ (normal: 120-250). Alanine transaminase (ALT), aspartate transaminase (AST) and gamma glutamyl transferase (GGT) levels were slightly elevated. FBC was normal.

A biopsy from the liver lesion was suggestive of high-grade non-Hodgkin's lymphoma (figure 4). The following markers showed positive immunostaining: CD45, MUM1, c-Myc, CD138, $\mathrm{Bcl} 2$ and Bcl6 (weak). Negative staining was noted for CD79a CD20, ALK, CD43, CD56, CD15, CD34 and chromogranin. Approximately $90 \%$ of tumour cells showed ki67 nuclear staining. $\mathrm{Bcl} 2$ gene rearrangement was not detected on FISH but did show loss of 3' end of the MYC locus. This was considered as an abnormality of uncertain significance. Expert anatomical pathology opinion was that the features were consistent with a CD20 negative, aggressive B-cell lymphoma, most likely PBL. The morphological and immunological features of original biopsy taken from L5 were found to be consistent with that of the liver biopsy. The International Prognostic Index (IPI) score was 3 (increased LDH, more than one extranodal site and stage IV).

She was started on chemotherapy regimen comprised of doseadjusted etoposide, prednisone, vincristine, cyclophosphamide, doxorubicin (DA-EPOCH). She also received bortezomib infusion and intrathecal cytarabine. A restaging PET performed after four cycles of chemotherapy showed progression of liver disease and SUVmax of 14.6. Subsequently, she proceeded to ifosfamide, carboplatin and etoposide (ICE) combination with bortezomib as salvage. A PET performed after two cycles of ICE showed a partial response particularly in the liver, and she proceeded to the third cycle. 
Table 1 Differential diagnosis of plasmablastic lymphoma (PBL)

\begin{tabular}{|c|c|c|c|}
\hline & PBL & DLBCL & Plasmablastic myeloma/plasmacytoma \\
\hline Clinical features & $\begin{array}{l}\text { Aggressive with poor prognosis (median survival } \\
6-12 \text { months) } \\
\text { Usually oral cavity location } \\
\text { Frequent association with immunodeficiency (HIV } \\
\text { infection, transplantation) } \\
\text { - EBV (+) } 50 \%-60 \%\end{array}$ & $\begin{array}{l}\text { Wide variety of presentation } \\
\text { Variable association with HIV } \\
\text { EBV rare }\end{array}$ & $\begin{array}{l}\text { Mostly immunocompetent } \\
\text { Usually EBV (-) } \\
\text { End-organ impairment }\end{array}$ \\
\hline Morphology & $\begin{array}{l}\text { Aggressive with poor prognosis (median survival } \\
6-12 \text { months) } \\
\text { Proliferation of large plasmablastic/immunoblastic } \\
\text { cells } \\
\text { Diffuse sheets of monomorphic cells } \\
\text { - Extraoral and immunocompetent cases have } \\
\text { plasmacytic differentiation }\end{array}$ & $\begin{array}{l}\text { Variable but characterised by diffuse } \\
\text { architecture dominated by centroblasts } \\
\text { on a centrocytic background } \\
\text { - Frequent mitotic figures and apoptosis }\end{array}$ & $\begin{array}{l}\text { Large plasma cells containing enlarged, } \\
\text { hyperchromatic nucleus with prominent } \\
\text { nucleoli } \\
\text { - Plasmablastic subtype virtually identical } \\
\text { to PBL }\end{array}$ \\
\hline Immunophenotype & $\begin{array}{l}\text { Positive for: CD138, CD38, CD79a, CD56 } \\
\text { Negative for CD20 }\end{array}$ & $\begin{array}{l}\text { Positive for: CD20, CD79a } \\
\text { Negative for CD138 }\end{array}$ & $\begin{array}{l}\text { Plasma cell phenotype: positive CD138, } \\
\text { CD38 } \\
\text { - Negative for CD20 }\end{array}$ \\
\hline
\end{tabular}

DLBCL, diffuse large B cell lymphoma.

After the third cycle, she presented with acute abdominal pain, fever and rapidly increasing LDH level ( $>5 \mathrm{X}$ upper limit of normal value). She was started on steroids in view of rapid clinical progression. Subsequent PET showed some persistent disease in the liver with no definite disease progression; however, its interpretation was problematic due to 5 days of steroid therapy.

Salvage was commenced with gemcitabine and vinorelbine and a period of clinical stability was achieved. As symptoms of disease progression returned, a PET performed after five cycles confirmed progression of disease. Gemcitabine-based chemotherapy was ceased and she started on lenalidomide and dexamethasone. Unfortunately, she could not tolerate lenalidomide due to rapid deterioration of liver function associated with upper abdominal pain that likely reflected further disease progression. She received a course of palliative radiotherapy to liver to control the abdominal pain.

\section{INVESTIGATIONS}

See above

\section{DIFFERENTIAL DIAGNOSIS}

Differential diagnosis consideration for PBL include a wide range of other lymphoid tumours ${ }^{1}{ }^{4}$ with immunoblastic, plasmablastic or plasmacytic or immunoblastic appearances, such as DLBCL with plasmacytic differentiation, plasmablastic myeloma and solitary plasmacytoma (table 1). A comparison of clinical features, morphology and immunophenotype is listed on the following table.

DLBCL include a wide of clinical and morphological presentations. These tumours can be differentiated from PBL on the basis of positive immunoreactivity for B cell markers, such as CD20 and CD79a. However, both PBL and plasmablastic plasma cells neoplasms share virtually identical morphological and immunophenotype features. Hence, the distinction between these two entities must be based on clinical differences: EBV positivity is usually associated with PBL, while end-organ damage presentation (ie, renal failure, anaemia, hypercalcaemia, renal impairment) favours a diagnosis of multiple myeloma.

\section{TREATMENT}

See above

\section{OUTCOME AND FOLLOW-UP}

As the last resort, she was commenced on nivolumab. Following the first cycle, she rapidly progressed to develop hepatic failure due to continuing progression of her disease and passed away around 16 months after the initial diagnosis.

\section{DISCUSSION}

PBL is a rare type of high-grade lymphoma frequently involving extranodal sites. HIV-negative PBL patients are known to present with relatively advanced clinical stage with B symptoms, and less common bone marrow involvement than in HIV- positive patients. ${ }^{3}$

Our patient initially presented like a typical solitary plasmacytoma. The fragmented histology sample taken from laminectomy procedure favoured plasma cell neoplasm. However, extensive crush artefacts and necrosis made it difficult to recognise lymphoma-related histological features. Therefore, we should highlight the importance to obtain adequate tissue samples to facilitate accurate diagnosis. After the confirmation of PBL on liver biopsy, the original sample taken from L5 lesion was compared with the liver cores. Both specimens showed identical histological and immunological features, which confirmed same pathological process.

One of the important differential diagnoses for PBL is plasmablastic myeloma. Absence of bone marrow involvement or hypercalcaemia/renal dysfunction in our patient makes plasmablastic myeloma an unlikely diagnosis.

To our knowledge, this is a first published report on HIV-negative PBL mimicking solitary plasmacytoma. In 2010, Castillo et $a l^{5}$ conducted a systematic review of 76 cases of HIV-negative PBL with predominately extraoral locations and reported a median survival time of 9 months and 2-year overall survival of only $10 \%$. Liu et al ${ }^{6}$ reviewed eight cases of HIV-negative patients with PBL who underwent chemotherapy and reported complete response in seven cases.

Unfortunately, her disease rapidly progressed to involve multiple sites, predominantly liver.

There is no well-established treatment regimen for PBL due to its rarity. Cyclophosphamide, hydroxydaunorubicin, oncovin and prednisolone (CHOP) is considered as a suboptimal treatment option and the National Comprehensive Cancer Network (NCCN) guideline recommends more aggressive therapy. ${ }^{7}$ One of the treatment options for patients with HIV-associated PBL is bortezomib alone or in combination with $\mathrm{CHOP}^{89}$ Another alternative is 
DA-EPOCH. ${ }^{10}$ Our patient was initially treated with DA-EDOCH with intrathecal cytarabine. The role of intrathecal chemotherapy as central nervous system (CNS) prophylaxis was not well studied. In view of frequent extranodal site involvement and aggressive natural history of disease, CNS prophylaxis was justified by some authors. ${ }^{3}$

Given the unfavourable outcome of PBL and expression of myeloma markers, clinicians frequently try agents that are not standard component of lymphoma management but are routinely used in the treatment of multiple myeloma. Proteasome inhibitors have been used in PBL with variable response. ${ }^{11-13}$ Unfortunately, our patient did not respond well to bortezomib/ chemotherapy combination.

Our patient failed to respond with the second and third lines of treatment (ICE and gemcitabine and vinorelbine, respectively). She could not tolerate lenalidomide. Lenalidomide based-chemotherapy has been shown to achieve good response in PBL. ${ }^{14-16}$ However, lenalidomide alone was seldom used in PBL. Interestingly, there are few case reports that has described dramatic response to singleagent lenalidomide in PBL. ${ }^{17}{ }^{18}$ Nivolumab is a programmed cell death protein 1 (PD-1) inhibitor that has shown anticancer activity in relapsed haematological malignancies. ${ }^{19}$ Our patient's disease rapidly progressed after first cycle of nivolumab and she died of hepatic failure 3 weeks later.

\section{Learning points}

- This is a first reported case of plasmablastic lymphoma (PBL) mimicking solitary plasmacytoma.

- The case once again emphasises the need for obtaining adequate tissue sample to facilitate accurate diagnosis on the first instance.

- Coexpression of myeloma and lymphoma markers should raise the suspicion of $\mathrm{PBL}$ in any patient.

Contributors RD conceived the work and wrote the article. He assisted with the literature research, image formatting for presentation in the journal, final editing and submission of the paper. LI-G was involved in the care of the patient and assisted writing the report. JA also oversaw the creation of the report and assisted in the clinical assessment of the patient. He helped in the production of the paper, literature review and final editing. JA is also responsible for the overall content as guarantor and approved the final draft.

Funding The authors have not declared a specific grant for this research from any funding agency in the public, commercial or not-for-profit sectors.

Competing interests None declared.

Patient consent Not required.

Provenance and peer review Not commissioned; externally peer reviewed.

Open access This is an open access article distributed in accordance with the Creative Commons Attribution Non Commercial (CC BY-NC 4.0) license, which permits others to distribute, remix, adapt, build upon this work non-commercially, and license their derivative works on different terms, provided the original work is properly cited and the use is non-commercial. See: http://creativecommons.org/ licenses/by-nc/4.0/

\section{REFERENCES}

1 Swerdlow SH. WHO classification of tumours of haematopoietic and lymphoid tissues. 4th ed. Lyon: IARC, 2017.

2 Morscio J, Dierickx D, Nijs J, et al. Clinicopathologic comparison of plasmablastic lymphoma in HIV-positive, immunocompetent, and posttransplant patients: singlecenter series of 25 cases and meta-analysis of 277 reported cases. Am J Surg Pathol 2014;38:875-86.

3 Castillo JJ, Bibas M, Miranda RN. The biology and treatment of plasmablastic lymphoma. Blood 2015:125:2323-30.

4 Harmon CM, Smith LB. Plasmablastic lymphoma: a review of clinicopathologic features and differential diagnosis. Arch Pathol Lab Med 2016;140:1074-8.

5 Castillo JJ, Winer ES, Stachurski D, et al. HIV-negative plasmablastic lymphoma: not in the mouth. Clin Lymphoma Myeloma Leuk 2011;11:185-9.

6 Liu JJ, Zhang L, Ayala E, et al. Human immunodeficiency virus (HIV)-negative plasmablastic lymphoma: a single institutional experience and literature review. Leuk Res 2011:35:1571-7.

7 Guidelines Version NCCN, 2014. AIDS-Related B-Cell lymphomas http://www.nccn. org/professionals/physician_gls/pdf/nhl.pdf (accessed 18 Sep 2014).

8 Bibas M, Grisetti S, Alba L, et al. Patient with HIV-associated plasmablastic lymphoma responding to bortezomib alone and in combination with dexamethasone, gemcitabine, oxaliplatin, cytarabine, and pegfilgrastim chemotherapy and lenalidomide alone. J Clin Oncol 2010;28:e704-8.

9 Fernandez-Alvarez R, Gonzalez-Rodriguez AP, Rubio-Castro A, et al. Bortezomib plus CHOP for the treatment of HIV-associated plasmablastic lymphoma: clinical experience in three patients. Leuk Lymphoma 2016:57:463-6.

10 Noy A, Lensing SY, Moore PC, et al. Plasmablastic lymphoma is treatable in the HAART era. A 10 year retrospective by the AIDS Malignancy Consortium. Leuk Lymphoma 1731;2016:57

11 Bibas M, Grisetti S, Alba L, et al. Patient with HIV-associated plasmablastic lymphoma responding to bortezomib alone and in combination with dexamethasone, gemcitabine, oxaliplatin, cytarabine, and pegfilgrastim chemotherapy and lenalidomide alone. J Clin Oncol 2010:28:e704-e708.

12 Cao C, Liu T, Zhu H, et al. Bortezomib-contained chemotherapy and thalidomide combined with CHOP (Cyclophosphamide, Doxorubicin, Vincristine, and Prednisone) play promising roles in plasmablastic lymphoma: a case report and literature review. Clin Lymphoma Myeloma Leuk 2014;14:e145-e150.

13 Castillo JJ, Reagan JL, Sikov WM, et al. Bortezomib in combination with infusional dose-adjusted EPOCH for the treatment of plasmablastic lymphoma. Br J Haematol 2015;169:352-5

14 Schmit JM, DeLaune J, Norkin M, et al. A case of plasmablastic lymphoma achieving complete response and durable remission after lenalidomide-based therapy. Oncol Res Treat 2017:40:46-8.

15 Yanamandra U, Sahu KK, Jain N, et al. Plasmablastic lymphoma: successful management with $\mathrm{CHOP}$ and lenalidomide in resource constraint settings. Ann Hematol 2016:95:1715-7.

16 Pretscher D, Kalisch A, Wilhelm M, et al. Refractory plasmablastic lymphoma-a review of treatment options beyond standard therapy. Ann Hematol 2017:96:967-70.

17 Carras S, Regny C, Peoc'h M, et al. Dramatic efficacy of low dose lenalidomide as single agent in a patient with refractory gastric non-human immunodeficiency virus associated plasmablastic lymphoma. Leuk Lymphoma 2015;56:2986-8.

18 Sher T, Miller KC, Lee K, et al. Remission induction with lenalidomide alone in a patient with previously untreated plasmablastic myeloma: a case report. Clin Lymphoma Myeloma 2009;9:328-30.

19 Lesokhin AM, Ansell SM, Armand P, et al. Nivolumab in Patients With Relapsed or Refractory Hematologic Malignancy: Preliminary Results of a Phase lb Study. J Clin Oncol 2016:34:2698-704.

Copyright 2018 BMJ Publishing Group. All rights reserved. For permission to reuse any of this content visit

http://group.bmj.com/group/rights-licensing/permissions.

BMJ Case Report Fellows may re-use this article for personal use and teaching without any further permission.

Become a Fellow of BMJ Case Reports today and you can:

- Submit as many cases as you like

Enjoy fast sympathetic peer review and rapid publication of accepted articles

- Access all the published articles

- Re-use any of the published material for personal use and teaching without further permission

For information on Institutional Fellowships contact consortiasales@bmjgroup.com

Visit casereports.bmj.com for more articles like this and to become a Fellow 